\title{
Colonization, regeneration potential and growth rates of fragments of the exotic aquatic macrophyte Hydrilla verticillata
}

\author{
Cristiane Akemi Umetsu' ${ }^{1}$ Heloísa Beatriz Antoniazi Evangelista ${ }^{2}$, \\ Sidinei Magela Thomaz ${ }^{1,2,3, *}$
}

\begin{abstract}
${ }^{1}$ Programa de Pós-graduação em Ecologia de Ambientes Aquáticos Continentais, ${ }^{2}$ Programa de Pós-graduação em Biologia Comparada and ${ }^{3}$ Departamento de Biologia e Núcleo de Pesquisas em Limnologia, Ictiologia e Aquicultura
\end{abstract} (Nupélia), Universidade Estadual de Maringá, Maringá, Paraná CEP 87020-900, Brazil

\begin{abstract}
Hydrilla verticillata is an aquatic macrophyte recently found in the Upper Paraná River floodplain. This species has a high potential to reproduce and disperse to new sites, mainly through stem fragments. In this study, we evaluated the colonization (the ability of roots to develop), regeneration (the ability of lateral shoots to develop) and growth rates of this species using fragments of different lengths that originated from different plant parts. We selected parts with and without apical tips, each 5 and $10 \mathrm{~cm}$ long, and the following hypothesis was tested: the fragments with apical tips have greater colonization and regeneration abilities than fragments without apical tips, and these abilities depend on the fragment length. Our results showed that both fragments with and without tips presented the same number and dry weight of roots and shoots and thus did not differ in their colonization or regeneration abilities. The length was important for the colonization ability, as $10 \mathrm{~cm}$ fragments produced more roots than $5 \mathrm{~cm}$ fragments. The high colonization and regeneration abilities from different fragments coupled with the high growth rates exhibited by $H$. verticillata may account for its rapid spread in novel habitats and its competitive success over native species. Thus, we suggest that the inadequate management of this species, resulting in the formation of fragments, especially of large lengths, may have important implications with regard to its infestation of new sites.
\end{abstract}

KEY WORDS: Fragmentation $\cdot$ Exotic species $\cdot$ Non-native species $\cdot$ Aquatic weed

\section{INTRODUCTION}

Aquatic systems are particularly prone to invasion by non-native species, including plants, invertebrates and vertebrates (García-Berthou et al. 2005), which negatively affect the entire aquatic environment through their impacts on both ecological and socioeconomic aspects (Coetzee et al. 2009). Each year, substantial amounts of money are spent on the management of invasive species infestations, either for their control or to reduce the probability of their reinvasion (Vitousek et al. 1997, Pimentel et al. 2001,
Januchowski-Hartley et al. 2011). Hydrilla verticillata (L.f.) Royle is a submerged aquatic macrophyte native to Asia and Australia (Cook \& Lüönd 1982) that is highly invasive and rated as the worst submerged weed in the USA (Langeland 1996) and one of the most undesirable weeds on the planet (Alix et al. 2009, Hofstra et al. 2010). The dense stands of this species interfere with recreational and commercial boating and can affect numerous other aspects of aquatic ecosystems (Hershner \& Havens 2008, Sousa 2011).

Hydrilla verticillata is mainly introduced to new habitats via vegetative fragments (Madsen \& Smith 
1999, Coetzee et al. 2009), and, due to this feature, the mechanical removal or harvesting of this species is rarely successful. Accordingly, the management of this species has proven to be problematic (Hershner \& Havens 2008). Stem fragments, which are mainly produced by the mechanical breakage of plants, float away from the original colonies and settle in the sediment (Madsen \& Smith 1999). These fragments exhibit 2 survival strategies: (1) the development of roots and rapid establishment in the sediment (colonization) and (2) the development of new propagules that can be dispersed (regeneration) (Southwood 1988, Barrat-Segretain \& Bornette 2000).

Hydrilla verticillata recently invaded the Upper Paraná River Floodplain (UPRF) in Brazil (Sousa et al. $2009,2010)$, and the potential for the spread of this exotic species is of particular concern because of the negative impacts associated with its occurrence in aquatic ecosystems (Posey et al. 1993, Hofstra et al. 1999, Wang et al. 2008). However, the main mechanism of dispersion/colonization of $H$. verticillata in the UPRF is most likely via small fragments (Sousa et al. 2009). Thus, to verify which type of fragments might increase the establishment success of this species, we evaluated the ability of $H$. verticillata to colonize, regenerate and grow from fragments that originated from different portions of the stems. To this end, we used fragments with different lengths and with the presence or absence of an apical tip. Previous studies showed that the apical portions of submerged macrophytes may have higher growth rates (Wu et al. 2007, Jiang et al. 2009), most likely due to apical dominance (Cline 1991), and larger fragments have greater colonization and regeneration abilities than smaller ones (Langeland \& Sutton 1980, Jiang et al. 2009, Riis et al. 2009). Thus, we tested the following hypothesis: fragments with apical tips have greater colonization and regeneration abilities than fragments without apical tips, and these abilities depend on the fragment length. According to this hypothesis, we predict that apical, larger tips will produce more new shoots and roots and will grow faster than smaller fragments lacking apical tips.

\section{MATERIALS AND METHODS}

Samples of Hydrilla verticillata were collected from the Itaipu Reservoir in April 2010. We collected undamaged plants and stored them in open plastic containers maintained with water collected from the same sites. In the laboratory, the healthy plants were selected and washed in tap water to remove any attached material. Then, portions were cut into 2 different fragment types: fragments with an apical tip (apical-stem) and fragments without an apical tip (mid-stem), both of 2 different lengths (5 and 10 $\mathrm{cm})$. For each fragment type, we selected 15 replicates, for a total of 60 samples. The fragments were individually placed in 0.81 translucent plastic containers $(15.5 \mathrm{~cm}$ in height; $10 \mathrm{~cm}$ in diameter) containing tap water, with $3 \mathrm{~cm}$ of substrate (horticultural peat). The substrate used in this experiment was chosen because it did not limit plant growth, as evidenced by a pilot experiment. The fragments were individually incubated to avoid intraspecific competition and were not planted in the substrate but simply dropped into the container. In a manner similar to that which occurs in nature (Langeland \& Sutton 1980), the fragments sank into the substrate and started rooting after a few days. The position of the plastic containers with the fragments was randomized in the greenhouse. The physical and chemical parameters of the water were measured weekly in all containers, and the growing conditions were found to be suitable for the fragments (water temperature of $17.86 \pm 0.50^{\circ} \mathrm{C}$, dissolved oxygen concentration of $9.68 \pm 0.66 \mathrm{mg} \mathrm{l}^{-1}, \mathrm{pH}$ of $7.94 \pm 0.76$ and conductivity of $254 \pm 7.07 \mu \mathrm{S} \mathrm{cm} \mathrm{cm}^{-1}$; mean \pm standard deviation). At the end of the experiment (38 d), any regeneration of new shoots or colonization by roots was assessed.

To evaluate colonization ability, we measured the number of roots and the root dry weight (DW, mg). To evaluate regeneration ability, we measured the number of shoots (defined as any secondary branch that emerged during the experiment) and the shoot DW (defined as the total weight of the new shoots that appeared during the experiment). To obtain DW, the material was oven-dried at $60^{\circ} \mathrm{C}$ until a constant weight was reached. Growth was defined as an increase in biomass (DW). The initial DW of each type of fragment was estimated by measuring 15 fragments of a similar size to those used in the experiment. The relative growth rates (RGR) were calculated for the fragments alone (considering only the growth of the original fragments and excluding the shoots and roots that appeared during the experiment) and the total biomass (considering the growth of the fragment plus new shoots and roots as the total investment in the growth and production of new biomass). The RGR was calculated as follows:

$$
\mathrm{RGR}=\left(\ln W_{\mathrm{f}}-\ln W_{\mathrm{i}}\right) / t_{\text {days }}
$$

where $W_{\mathrm{f}}=$ the final DW, $W_{\mathrm{i}}=$ the initial DW and $t_{\text {days }}=$ time in days 
We used a 2-way ANOVA to test the effect of the fragment type (with and without apical tip) and length and the interactions between them on the number and DW of the shoots and roots, and on the fragment and total RGR. When an interaction was significant, we applied the decomposition of treatment degrees of freedom (DF analysis) in which the degrees of freedom were rearranged to compare the levels of a factor within the levels of other factors (Hinkelmann \& Kempthorne 2005). This analysis explores the nature of the interaction by examining the difference between the groups within one level of one of the independent variables, whereby each factor can be analyzed as a fixed factor while varying the levels of another factor. We applied a Bonferroni correction for adjusting the significance levels to control the Type I error rates in multiple testing situations. Thus, the level of significance of the tests was set at 0.0083 . The multiple comparisons were performed using Tukey's test. The statistical analyses were performed using $\mathrm{R}$ v.2.11.1.
Table 1. Two-way ANOVA for effects of type and length and their interactions on the shoot number, shoot dry weight (DW), root number, root DW and fragment and total relative growth rate (RGR). * Significant following Bonferroni correction at a level of 0.0083 ; df1, df2 represent degrees of freedom between groups and within groups, respectively

\begin{tabular}{|c|c|c|c|c|c|c|}
\hline \multirow{2}{*}{$\begin{array}{l}\text { Variable } \\
\text { response }\end{array}$} & \multicolumn{3}{|c|}{ - Tests -} & \multicolumn{3}{|c|}{ Treatments } \\
\hline & df1 & df2 & $F / \mathrm{p}$ & $\begin{array}{l}\text { Type } \\
\text { (T) }\end{array}$ & $\begin{array}{l}\text { Length } \\
\text { (L) }\end{array}$ & $\mathrm{T} \times \mathrm{L}$ \\
\hline \multirow[t]{2}{*}{ Shoot number } & 1 & 54 & $F$ & 0.909 & 4.222 & 0.081 \\
\hline & & & $\mathrm{p}$ & 0.344 & 0.044 & 0.776 \\
\hline \multirow[t]{2}{*}{ Shoot DW } & 1 & 54 & $F$ & 6.779 & 8.050 & 0.182 \\
\hline & & & $\mathrm{p}$ & 0.011 & $0.006^{*}$ & 0.670 \\
\hline \multirow[t]{2}{*}{ Root number } & 1 & 54 & $F$ & 0.160 & 11.17 & $<0.001$ \\
\hline & & & $\mathrm{p}$ & 0.690 & $0.001^{*}$ & 0.989 \\
\hline \multirow[t]{2}{*}{ Root DW } & 1 & 54 & $F$ & 0.363 & 2.182 & 0.255 \\
\hline & & & $\mathrm{p}$ & 0.548 & 0.145 & 0.615 \\
\hline \multirow[t]{2}{*}{ Fragment RGR } & 1 & 54 & $F$ & 9.925 & 2.582 & 31.89 \\
\hline & & & $\mathrm{p}$ & $0.002^{*}$ & 0.113 & $<0.001^{*}$ \\
\hline \multirow[t]{2}{*}{ Total RGR } & 1 & 54 & $F$ & 1.209 & 2.111 & 21.17 \\
\hline & & & $\mathrm{p}$ & 0.276 & 0.152 & $<0.001^{*}$ \\
\hline
\end{tabular}

\section{RESULTS}

All fragments of Hydrilla verticillata survived the duration of the experiment, with the exception of a single $5 \mathrm{~cm}$ apical-stem fragment and a single $5 \mathrm{~cm}$ mid-stem fragment that did not develop. Our results showed that the fragment type (with and without an apical tip) did not significantly affect the colonization or regeneration abilities of the fragment (Table 1, Fig. 1a-d). The number and DW (mg) of the shoots per fragment did not differ between the apical-stem $(1.65 \pm 1.42,0.010 \pm 0.007)$ and midsterm fragments $(1.96 \pm 1.08$ and $0.013 \pm$ 0.007) (Fig. 1a,b). Similarly, no differences were found in the number and DW of roots per fragment: the apicalstems did not differ from the mid-stems $(2.37 \pm 1.37,0.003 \pm 0.002$ and $2.24 \pm 1.45$, $0.002 \pm 0.003$, respectively) (Fig. 1c,d).

However, the length of fragments significantly affected the number of roots and shoot DW (Table 1). Overall, the $10 \mathrm{~cm}$ fragments developed a greater number of roots $(2.86 \pm 1.47)$ and a higher shoot DW $(0.013 \pm 0.008)$ (Fig. 1b,c) than the $5 \mathrm{~cm}$ fragments $(1.71 \pm 1.04$ and $0.007 \pm 0.006$, respectively). No signifi-
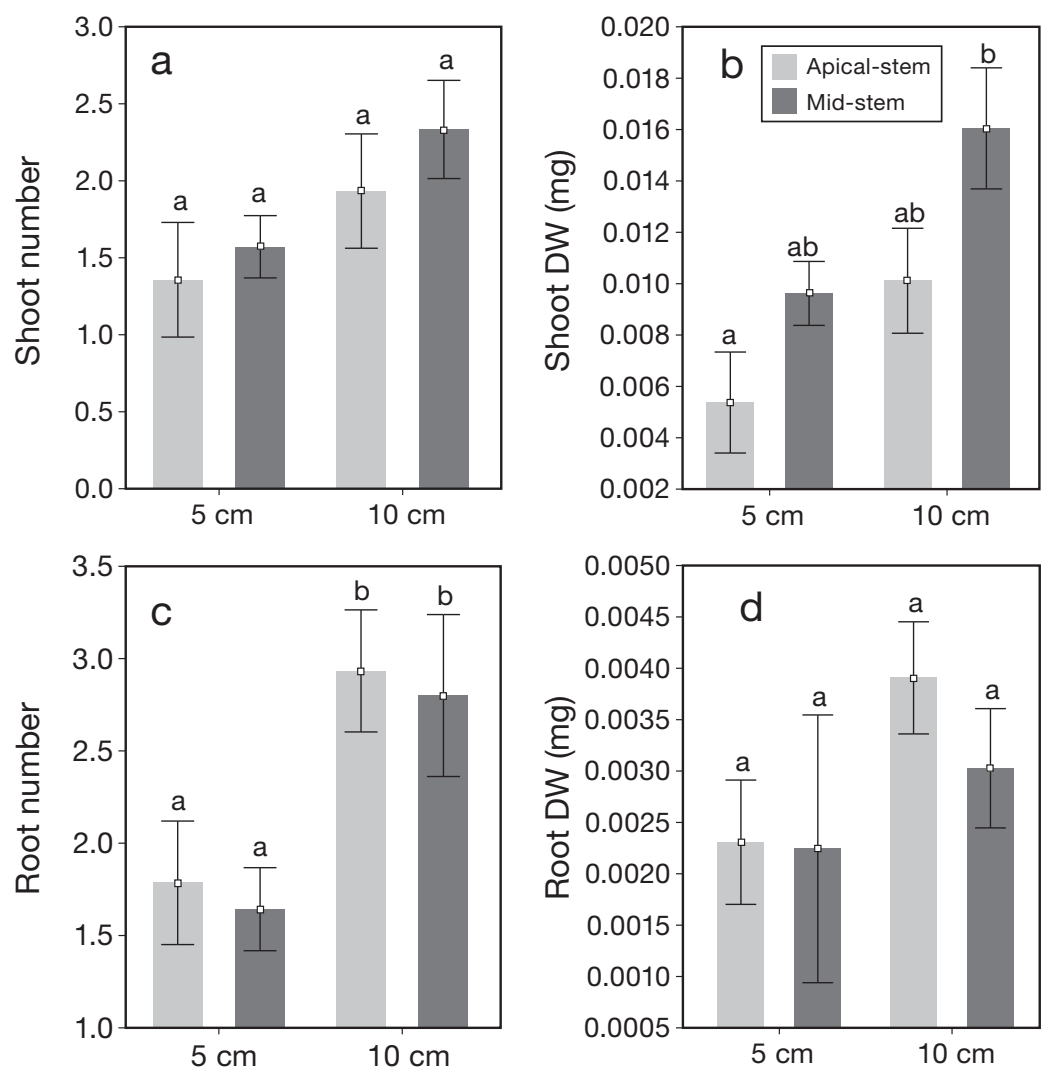

Fig. 1. Mean $( \pm \mathrm{SE})(\mathrm{a})$ shoot number, (b) shoot dry weight (DW), (c) root number and (d) root DW per fragment of apical-stem and mid-stem fragments of 5 and $10 \mathrm{~cm}$ length. Matching letters above columns indicate no significant differences 
Table 2. Two-factor interaction effects on fragment relative growth rate (RGR). (a) Levels of factor 'length' $(5 \mathrm{~cm} ; 10 \mathrm{~cm})$ within the levels of factor 'type' (AS = apical-stem; MS = mid-stem fragments): in this case, we fixed the levels AS and MS and varied the levels $5 \mathrm{~cm}$ and $10 \mathrm{~cm}$. (b) Levels of factor 'type' within the levels of factor 'length': here we fixed the levels $5 \mathrm{~cm}$ and $10 \mathrm{~cm}$ and varied the levels AS and MS. *Significant following Bonferroni correction at a level of 0.0083

\begin{tabular}{|lcccrr|}
\hline Source of variation & df & $\begin{array}{c}\text { Sum of } \\
\text { squares }\end{array}$ & $\begin{array}{c}\text { Mean } \\
\text { square }\end{array}$ & $F$ & $\mathrm{p}$ \\
\hline a) & & & & & \\
Type & 1 & 0.0008 & 0.0008 & 9.9264 & $0.0027^{*}$ \\
Type $\times$ Length & 2 & 0.0026 & 0.0013 & 17.2407 & $<0.0001^{*}$ \\
AS $(5 \mathrm{~cm} ; 10 \mathrm{~cm})$ & 1 & 0.0006 & 0.0006 & 8.1648 & $0.0061^{*}$ \\
MS $(5 \mathrm{~cm} ; 10 \mathrm{~cm})$ & 1 & 0.0020 & 0.0020 & 26.3178 & $<0.0001^{*}$ \\
Residuals & 54 & 0.0041 & 0.0001 & & \\
b) & & & & & \\
Length & 1 & 0.0002 & 0.0002 & 2.5825 & 0.1139 \\
Length $\times$ Type & 2 & 0.0032 & 0.0016 & 20.9124 & $<0.0001^{*}$ \\
$5 \mathrm{~cm}(\mathrm{AS} ; \mathrm{MS})$ & 1 & 0.0029 & 0.0029 & 39.0746 & $<0.0001^{*}$ \\
$10 \mathrm{~cm}(\mathrm{AS} ; \mathrm{MS})$ & 1 & 0.0002 & 0.0002 & 2.7501 & 0.1030 \\
Residuals & 54 & 0.0041 & 0.0001 & & \\
\hline
\end{tabular}

cantly higher fragment RGR than the mid-stem fragments (Table 2b, Fig. 2a). In contrast, when we fixed the level '10 $\mathrm{cm}^{\prime}$, there was no significant difference between the apical-stem and midstem fragments (Table 2b, Fig. 2a).

There was a significant interaction between the effects of the fragment type and length on the total RGR (Table 1). When we fixed the level 'apical-stem' of the factor 'type' and varied the levels of factor 'length', the 5 and $10 \mathrm{~cm}$ fragments did not affect the total RGR (Table 3a, Fig. 2b). However, when we fixed the level 'mid-stem', the $10 \mathrm{~cm}$ fragments exhibited greater values than the $5 \mathrm{~cm}$ fragments (Fig. 2b). When we fixed the level ' $5 \mathrm{~cm}$ ' of the factor 'length' and varied the levels of the factor 'type', the apical-stem fragments had higher values of total RGR than the mid-stem fragments (Table $3 b$, cant interactions occurred between the fragment type and length with respect to the number and DW of the shoots and roots.

The type of fragment significantly affected the fragment RGR and was dependent on the fragment length, as a significant interaction occurred between the type and length (Table 1). The interaction analysis showed that, when we fixed the level 'apicalstem' of the factor 'type' and varied the levels of the factor 'length' (5 and $10 \mathrm{~cm}$ ), the $5 \mathrm{~cm}$ fragments had a significantly higher RGR than the $10 \mathrm{~cm}$ fragments (Table 2a, Fig. 2a), whereas, when we fixed the level 'mid-stem', the $10 \mathrm{~cm}$ fragments showed the highest RGR (Table 2a, Fig. 2a).

When we fixed the level ' $5 \mathrm{~cm}$ ' of the factor 'length' and varied the factor 'type' levels (apical-stem and mid-stem), the apical-stem fragments had signifi-
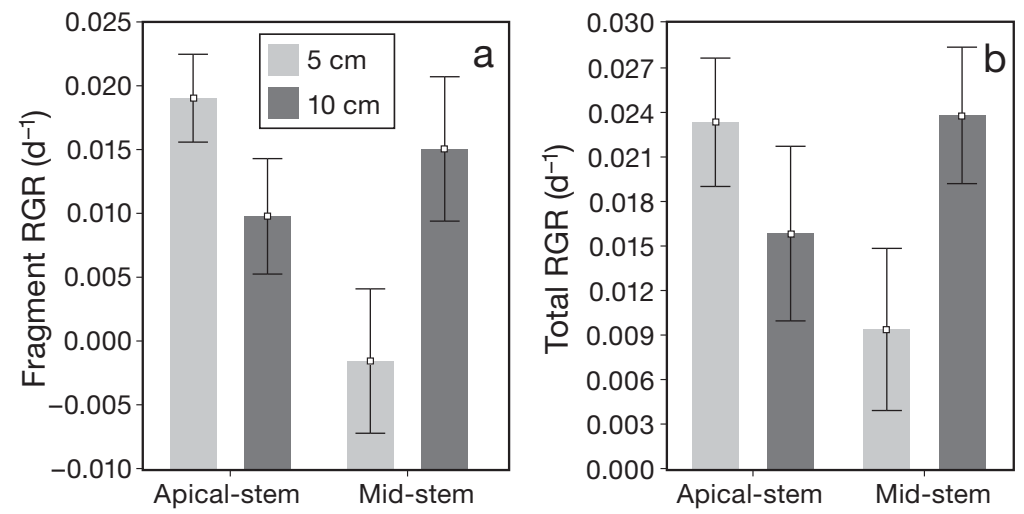

Fig. 2. Mean ( \pm SE) (a) fragment and (b) total relative growth rate (RGR) of apical-stem and mid-stem fragments of 5 and $10 \mathrm{~cm}$ length
Fig. 2b). Conversely, when we fixed the level ' $10 \mathrm{~cm}$ ', the types of fragment showed no difference in the total RGR (Table 3b, Fig. 2b).

\section{DISCUSSION}

Our results showed that Hydrilla verticillata is able to colonize (root formation) and regenerate (shoot production) through fragments with or without tips. The opposite results were found by Riis et al. (2009) for other aquatic macrophytes, such as Potamogeton perfoliatus and Elodea canadensis, which presented greater colonization and regeneration abilities when their fragments had apical tips. In contrast, the length of the fragment influenced the colonization ability, as est number of roots. In addition, the $10 \mathrm{~cm}$ fragments had the greatest shoot biomass. In general, larger fragments of several other macrophyte species present greater root formation and shoot production than smaller fragments (Wu et al. 2007, Jiang et al. 2009, Riis et al. 2009).

The growth of a fragment and the total growth (investment in the fragment growth itself together with the production of new shoots and roots) are influenced by the interactions between the type and length of the fragment. The DF analysis showed that the apical-stem fragments had greater growth rates when they were $5 \mathrm{~cm}$ long, the larger fragments (i.e. $10 \mathrm{~cm}$ ) developed the high- 
Table 3. Two-factor interaction effects on total relative growth rate (RGR). (a) Levels of factor 'length' $(5 \mathrm{~cm} ; 10 \mathrm{~cm})$ within the levels of factor 'type' (AS = apical-stem; MS = mid-stem fragments). (b) Levels of factor 'type' within the levels of factor 'length'. "Significant following Bonferroni correction at a level of 0.0083

\begin{tabular}{|lcccrc|}
\hline Source of variation & df & $\begin{array}{c}\text { Sum of } \\
\text { squares }\end{array}$ & $\begin{array}{c}\text { Mean } \\
\text { square }\end{array}$ & $F$ & $\mathrm{p}$ \\
\hline a) & & & & & \\
Type & 1 & 0.0000 & 0.0000 & 1.2098 & 0.2762 \\
Type $\times$ Length & 2 & 0.0019 & 0.0009 & 11.6437 & $0.0001^{*}$ \\
AS $(5 \mathrm{~cm}-10 \mathrm{~cm})$ & 1 & 0.0004 & 0.0004 & 4.9576 & $0.0301^{*}$ \\
MS $(5 \mathrm{~cm}-10 \mathrm{~cm})$ & 1 & 0.0015 & 0.0015 & 18.3298 & $0.0001^{*}$ \\
Residuals & 54 & 0.0044 & 0.0000 & & \\
b) & & & & & \\
Length & 1 & 0.0001 & 0.0001 & 2.1110 & 0.1520 \\
Length $\times$ Type & 2 & 0.0018 & 0.0009 & 11.1931 & $<0.0001^{*}$ \\
5 cm (AS - MS) & 1 & 0.0013 & 0.0013 & 16.5959 & $0.0001^{*}$ \\
10 cm (AS - MS) & 1 & 0.0004 & 0.0004 & 5.7903 & 0.0195 \\
Residuals & 54 & 0.0041 & 0.0001 & & \\
\hline
\end{tabular}

Stem breakage through physical disturbance is required to form a large number of fragments of Hydrilla verticillata (Madsen \& Smith 1999), and our results suggest that this species can successfully establish when it produces and disperses both apical- and mid-stem fragments, especially when the latter have substantial lengths $(10 \mathrm{~cm})$. Therefore, this indifference in the colonization and regeneration abilities of the distinct fragment types could provide $H$. verticillata with a competitive advantage over native species. In fact, a recent study showed that this species produces, on average, more shoots and roots, regardless of the fragment type, compared to 2 other species of same family Hydrocharitaceae: Egeria densa and E. najas (C. A. Umetsu unpubl. data).

whereas the mid-stem fragments grew faster when they were $10 \mathrm{~cm}$ long. The smaller increase in the fragment and total biomass values for the mid-stems at $5 \mathrm{~cm}$ compared to the other treatments (Fig. 2a,b) indicated that the larger fragments invest in their own enlargement and in the production of new shoots and roots more efficiently. As noted by Riis et al. (2009) for other aquatic macrophytes, short fragments have smaller amounts of photosynthetic tissue and reserves (e.g. carbohydrates) stored as biomass, hampering their prompt investment in shoot and root production compared with long fragments. However, short apical fragments have apical meristems (regions with active cell growth) that enable the plant to invest promptly in vertical growth, increasing both light acquisition and biomass, thus supporting the concept of apical dominance (Cline 1991). This concept proposes that fragments with apical tips invest more energy into growth due to the presence of the apical meristem, whereas mid-stems invest more energy into the production of lateral shoots. Long fragments seem to divide energy investment equally into the production of roots, new shoots and growth to form a complete plant.

Thus, our prediction that the larger fragments with tips would produce more new shoots and roots, and grow faster than the smaller fragments without apical tips was only partially validated since $10 \mathrm{~cm}$ length fragments are able to produce shoots and roots, independently of type of fragment. With regard to the growth rates, the apical-stem fragments were more efficient in growth only when they were $5 \mathrm{~cm}$ long, as the apical- and mid-stem fragments did not differ in their growth rates when they were $10 \mathrm{~cm}$ long.
The ability of Hydrilla verticillata to efficiently produce shoots and roots from different fragments may partially explain its successful dispersal and invasion into novel environments. A high level of shoot production can promote invasion because propagule pressure is a determining factor for the successful invasion of some species (Lockwood et al. 2005, Von Holle \& Simberloff 2005, Chadwell \& Engelhardt 2008). Moreover, a greater production of roots may favor anchorage in the sediment, overcoming the disturbance caused by water flow (Barrat-Segretain 2001, Bornette \& Puijalon 2011) and also allowing the plant to fulfill its nutrient requirements.

In addition to a high capacity for colonization and regeneration from different types of fragments, the large values of RGR displayed by Hydrilla verticillata could be the reason for its competitive success. Studies suggest that this exotic species can suppress the growth of other submerged macrophytes, especially those with lower growth rates (Wang et al. 2008, Bianchini et al. 2010, Sousa 2011), including native species of the same family such as Egeria densa (Mony et al. 2007) and E. najas (Sousa et al. 2010).

In general, human activities have accelerated the invasion process of many organisms (Johnstone et al. 1985, Chapin et al. 2000, Kolar \& Lodge 2001), mainly due to the inadvertent introduction of species outside of their native range. Hydrilla verticillata recently invaded aquatic ecosystems in Brazil, and the consequences of its introduction are yet unknown (Sousa 2011). Our results demonstrate that the inappropriate management of this species with various mechanical control techniques, which can result in the release of 
fragments, may have important implications with respect to the infestation of new sites by this species. We suggest that a release of fragments caused by the mechanical removal of $H$. verticillata biomass may have the potential to increase its successful establishment.

Acknowledgements. We acknowledge with appreciation 3 reviewers whose suggestions improved considerably our manuscript. C.A.U. and H.B.A.E. acknowledge the Brazilian Council of Research (CNPq). We also thank R. P. Mormul and D. T. Batista for their helpful remarks on the statistical analyses. S.M.T. is especially thankful to CNPq for continuous funding through a Research Productivity Grant. This research was funded by CNPq/MCT through the LongTerm Ecological Research Program, site number 6, and by Itaipu Binacional.

\section{LITERATURE CITED}

Alix MS, Scribailo RW, Price JD (2009) Hydrilla verticillata (Hydrocharitaceae): an undesirable addition to Indiana's aquatic flora. Rhodora 111:131-136

> Barrat-Segretain MH (2001) Biomass allocation in three macrophyte species in relation to the disturbance level of their habitat. Freshw Biol 46:935-945

Barrat-Segretain MH, Bornette G (2000) Regeneration and colonization abilities of aquatic plant fragments: effect of disturbance seasonality. Hydrobiologia 421:31-39

Bianchini I Jr, Cunha-Santino MB, Milan JAM, Rodrigues CJ, Dias JHP (2010) Growth of Hydrilla verticillata (L. f.) Royle under controlled conditions. Hydrobiologia 644:301-312

> Bornette G, Puijalon S (2011) Response of aquatic plants to abiotic factors: a review. Aquat Sci 73:1-14

> Chadwell TB, Engelhardt KAM (2008) Effects of pre-existing submerged vegetation and propagule pressure on the invasion success of Hydrilla verticillata. J Appl Ecol 45:515-523

> Chapin FS III, Zavaleta ES, Eviner VT, Naylor RL and others (2000) Consequences of changing biodiversity. Nature 405:234-242

Cline MG (1991) Apical dominance. Bot Rev 57:318-358

Coetzee JA, Hill MP, Schlange D (2009) Potential spread of the invasive plant Hydrilla verticillata in South Africa based on anthropogenic spread and climate suitability. Biol Invasions 11:801-821

Cook CDK, Lüönd R (1982) A revision of the genus Hydrilla (Hydrocharitaceae). Aquat Bot 13:485-504

> García-Berthou E, Alcaraz C, Pou-Rovira Q, Zamora L, Coenders G, Feo C (2005) Introduction pathways and establishment rates of invasive aquatic species in Europe. Can J Fish Aquat Sci 62:453-463

> Hershner C, Havens KJ (2008) Managing invasive aquatic plants in a changing system: strategic consideration of ecosystem services. Conserv Biol 22:544-550

Hinkelmann K, Kempthorne O (2005) Design and analysis of experiments: introduction to experimental design. John Wiley \& Sons, New York

- Hofstra D, Clayton J, Green JD, Auger M (1999) Competitive performance of Hydrilla verticillata in New Zealand. Aquat Bot 63:305-324

> Hofstra D, Champion P, Clayton J (2010) Predicting invasive success of Hydrilla verticillata (L.f.) Royle in flowing water. Hydrobiologia 656:213-219

Januchowski-Hartley SR, Visconti P, Pressey RL (2011) A systematic approach for prioritizing multiple management actions for invasive species. Biol Invasions 13:1241-1253

Jiang J, An S, Zhou C, Guan B, Sun Z, Cai Y, Liu F (2009) Fragment propagation and colonization ability enhanced and varied at node level after escaping from apical dominance in submerged macrophytes. J Integr Plant Biol 51: 308-315

Johnstone IM, Coffey BT, Howard-Williams C (1985) The role of recreational boat traffic in interlake dispersal of macrophytes: a New Zealand case study. J Environ Manage 20:263-279

Kolar CS, Lodge DM (2001) Progress in invasion biology: predicting invaders. Trends Ecol Evol 16:199-204

Langeland KA (1996) Hydrilla verticillata (L.F.) Royle (Hydrocharitaceae), 'The perfect aquatic weed'. Castanea 61: 293-304

Langeland KA, Sutton DL (1980) Regrowth of hydrilla from axillary buds. J Aquat Plant Manage 18:27-29

$>$ Lockwood JL, Cassey P, Blackburn T (2005) The role of propagule pressure in explaining species invasion. Trends Ecol Evol 20:223-228

Madsen JD, Smith DH (1999) Vegetative spread of dioecious hydrilla colonies in experimental ponds. J Aquat Plant Manage 37:25-29

> Mony C, Koschnick TJ, Haller WT, Muller S (2007) Competition between two invasive Hydrocharitaceae (Hydrilla verticillata (L.f.) (Royle) and Egeria densa (Planch)) as influenced by sediment fertility and season. Aquat Bot 86:236-242

Pimentel D, McNair S, Janecka J, Wightman J and others (2001) Economic and environmental threats of alien plant, animal, and microbe invasions. Agric Ecosyst Environ 84:1-20

> Posey MH, Wigand C, Stevenson JC (1993) Effects of an introduced aquatic plant, Hydrilla verticillata, on benthic communities in the Upper Chesapeake Bay. Estuar Coast Shelf Sci 37:539-555

Riis T, Madsen TV, Sennels RSH (2009) Regeneration, colonization and growth rates of allofragments in four common stream plants. Aquat Bot 90:209-212

Sousa WTZ (2011) Hydrilla verticillata (Hydrocharitaceae), a recent invader threatening Brazil's freshwater environments: a review of the extent of the problem. Hydrobiologia 669:1-20

Sousa WTZ, Thomaz SM, Murphy KJ, Silveira MJ, Mormul RP (2009) Environmental predictors of the occurrence of exotic Hydrilla verticillata (L.f.) Royle and native Egeria najas Planch. in a sub-tropical river floodplain: the Upper River Paraná, Brazil. Hydrobiologia 632:65-78

> Sousa WTZ, Thomaz SM, Murphy KJ (2010) Response of native Egeria najas Planch. and invasive Hydrilla verticillata (L.f.) Royle to altered hydroecological regime in a subtropical river. Aquat Bot 92:40-48

Southwood TRE (1988) Tactics, strategies and templets. Oikos 52:3-18

Vitousek PM, D'Antonio CM, Loope LL, Rejmánek M, Westbrooks R (1997) Introduced species: a significant component of human-caused global change. N Z J Ecol 21:1-16

> Von Holle B, Simberloff D (2005) Ecological resistance to biological invasion overwhelmed by propagule pressure. Ecology 86:3212-3218

> Wang JW, Yu D, Xiong W, Han YQ (2008) Above- and belowground competition between two submerged macrophytes. Hydrobiologia 607:113-122

Wu Z, Zuo J, Ma J, Wu J, Cheng S, Liang W (2007) Establishing submerged macrophytes via sinking and colonization of shoot fragments clipped off manually. Wuhan Univ J Nat Sci 12:553-557 